\title{
TO EVALUATE EFFICACY OF CYCLOSPORINE 0.1\% EYE DROPS AS MAINTENANCE THERAPY IN PATIENTS OF ALLERGIC CONJUNCTIVITIS
}

\author{
Bhavani Raina1, Sanjay Kai², Pallavi Sharma³, Anuradha Bharti ${ }^{4}$
}

${ }_{1}^{1}$ Lecturer, Department of Ophthalmology, Government Medical College, Jammu, Jammu and Kashmir, India.

${ }^{2}$ Associate Professor, Department of Ophthalmology, Government Medical College, Jammu, Jammu and Kashmir, India.

${ }^{3}$ Registrar, Department of Ophthalmology, Government Medical College, Jammu, Jammu and Kashmir, India.

${ }_{4}^{4}$ Registrar, Department of Ophthalmology, Government Medical College, Jammu, Jammu and Kashmir, India.

\section{ABSTRACT}

\section{BACKGROUND}

About $20-30 \%$ of world population is affected with allergic conjunctivitis. Topical steroids are considered as the mainstay of treatment for severe allergic conjunctivitis. However, steroids are associated with rise in intraocular pressure with subsequent glaucoma, cataract formation and increased susceptibility to microbial infections. This has produced a need to look for other options to treat allergic conjunctivitis. Cyclosporine appears to be a good candidate as it inhibits T- cell inhibition which is an important component of ocular surface inflammation.

Aims and Objectives- To evaluate the efficacy and safety of cyclosporine $0.1 \%$ eye drops as maintenance therapy in patients of allergic conjunctivitis.

\section{MATERIALS AND METHODS}

This uncontrolled clinical trial study was conducted on 50 patients suffering from mild to moderate allergic conjunctivitis attending the Eye OPD of Government Medical College, Jammu who were receiving the treatment in the form of steroid (loteprednol) eyedrops and had shown improvement with control of both signs as well symptoms of allergy. These patients were put on cyclosporine $0.1 \%$ eye drops after stopping the previous medication and evaluated for signs and symptoms at baseline (day 0 ), 2 weeks, 4 weeks and 12 weeks.

\section{RESULTS}

Out of 50 patients, 2 patients were lost to follow-up after $2^{\text {nd }}$ week, 4 patients had to be shifted to steroids due to worsening of disease after $2^{\text {nd }}$ and $4^{\text {th }}$ week. Remaining 44 patients completed the study with male to female ratio of $1.75: 1$. All symptoms like itching, discharge, photophobia and watering showed significant improvement at $12^{\text {th }}$ week as compared to baseline. Signs of conjunctival hyperemia and papillary hypertrophy showed significant reduction from $4^{\text {th }}$ week onwards and were maximum at $12^{\text {th }}$ week. The other two signs of Horner Trantas spots and punctate keratitis also showed improvement, but it was not significant as compared to baseline scores.

\section{CONCLUSION}

Topical cyclosporine $0.1 \%$ eye drops can be used to control and improve signs and symptoms of allergic conjunctivitis after the acute phase has been treated with steroids. Also, cyclosporine is safe for topical use.

\section{KEY WORDS}

Allergic Conjunctivitis, Cyclosporine $0.1 \%$.

HOW TO CITE THIS ARTICLE: Raina B, Kai S, Sharma P, et al. To evaluate efficacy of cyclosporine 0.1\% eye drops as maintenance therapy in patients of allergic conjunctivitis. J. Evolution Med. Dent. Sci. 2018;7(46):5021-5024, DOI: 10.14260/jemds/2018/1117

\section{BACKGROUND}

This Study of Twenty to thirty per cent of the world population is affected by allergic conjunctivitis. ${ }^{1}$ Allergic conjunctivitis is broadly divided into five subtypes: seasonal allergic conjunctivitis (SAC), perennial allergic conjunctivitis (PAC), vernal keratoconjunctivitis (VKC), atopic keratoconjunctivitis (AKC) and giant papillary conjunctivitis (GPC). While in majority of the patients it runs a mild course, it can result in considerable cost in terms of loss of productivity and reduction in quality of life.

'Financial or Other Competing Interest': None.

Submission 28-09-2018, Peer Review 24-10-2018,

Acceptance 30-10-2018, Published 12-11-2018.

Corresponding Author:

Sanjay Kai,

House No. 39, Canal Road,

Reminder Nagar, Jammu,

Jammu and Kashmir, India.

E-mail: drsanjaykai@gmail.com

DOI: $10.14260 /$ jemds/2018/1117

\section{(c) $(1) \ominus$}

Topical steroids are considered as the mainstay of treatment for severe allergic conjunctivitis. However, steroids are associated with rise in intraocular pressure (IOP) with subsequent glaucoma, cataract formation and increased susceptibility to microbial infections. This warrants cautious use of topical steroids and a need to look for other options to treat allergic conjunctivitis with a need to address its complex, chronic and multifactorial pathogenesis. Cyclosporine appears to be a good candidate as it inhibits Tcell inhibition which is an important component of ocular surface inflammation. ${ }^{2}$ It also has a direct inhibitory effect on eosinophil and mast cell activation. ${ }^{3}$ It is free from the potential adverse effects caused by the steroids. It is a cyclic polypeptide consisting of 11 amino acids produced from a metabolite of fungus species Beauveria nivea.

Topical cyclosporine has been tried in clinical studies in concentrations varying from $0.05 \%$ to $2 \%$ for the management of allergic conjunctivitis. However, as only limited literature is available, this study was undertaken to evaluate the efficacy and safety of cyclosporine $0.1 \%$ eye 
drops as maintenance therapy in patients of allergic conjunctivitis.

\section{MATERIALS AND METHODS}

This uncontrolled clinical trial study was conducted on 50 patients suffering from mild to moderate allergic conjunctivitis ${ }^{4}$ attending the Eye OPD of Government Medical College, Jammu between October 2017 and July 2018 who were receiving treatment in the form of steroid (Loteprednol $0.5 \%$ ) eye drops and had shown improvement with control of both signs as well as symptoms of allergy. A detailed history and ocular examination of all patients enrolled for the study was done after taking a written and informed consent from them. The patients were put on cyclosporine $0.1 \%$ eyedrops two times a day after stopping their previous medication and then evaluated for the symptoms (Itching, discharge, photophobia and watering) and signs (Conjunctival hyperemia, papillary hypertrophy, Horner Trantas spots and punctata keratitis) and subsequently graded as described below at baseline, on $2^{\text {nd }}$ week, 4 th week, and $12^{\text {th }}$ week. Grading was done according to prefixed scale and scores assigned. 5

\section{Inclusion Criteria}

- Age between 5-30 years.

- All patients of allergic conjunctivitis (vernal keratoconjunctivitis, perennial allergic conjunctivitis, seasonal allergic conjunctivitis) who were receiving treatment for more than 1 month.

\section{Exclusion Criteria}

- Contact lens users.

- Ocular trauma or recent ocular surgery.

- Patients on oral steroids.

- $\quad$ Pregnant or lactating females.

\section{Grading of Symptoms: (Itching, Discharge, Photophobia and Watering) \\ 0 No symptoms. \\ 1 Mild discomfort just noticeable. \\ 2 Moderate discomfort present most of the time, not interfering with routine activities. \\ 3 Severe discomfort interfering with routine activities.}

\author{
Grading of Signs \\ Conjunctival Hyperaemia \\ 0 Normal quiet eye. \\ 1 Mild, slightly dilated vessels. \\ 2 Moderate, dilation more apparent. \\ 3 Severe, numerous and obvious dilated vessels.

\section{Papillary Hypertrophy} \\ 0 No evidence. \\ 1 Mild papillary hypertrophy. \\ 2 Moderate hypertrophy with hazy view of tarsal vessels. \\ 3 Severe hypertrophy with non-visualisation of tarsal \\ vessels.
}

\footnotetext{
Horner Trantas Spots

0 Absent.

1 1-2 spots.

2 3-4 spots.

3 More than 4 spots.
}

\author{
Punctate Keratitis \\ $0 \quad$ No evidence. \\ 1 In one quadrant. \\ 2 In two quadrants. \\ 3 Three or more quadrants.
}

\section{Statistical Methods}

Statistical analysis was done using SPSS Version 22.0. The intra-group and inter-group changes in symptoms and signs during the course of study were compared. Comparison of mean values of symptoms at baseline and at different time intervals was done by unpaired $t$ test. Threshold for statistical significance was fixed at $\mathrm{P}=0.05$.

\section{RESULTS}

A total of 50 patients were enrolled in the study who fulfilled inclusion criteria. This included $32(64 \%)$ males and 18 (36\%) females (Table 1; Fig. 1). Out of these, 2 patients were lost to follow-up (After $2^{\text {nd }}$ week) and 4 patients had to be shifted to steroids due to worsening of disease ( 2 at $2^{\text {nd }}$ and 2 at $4^{\text {th }}$ week). Thus, 44 patients completed the study which included $63.64 \%$ males and $36.36 \%$ females. Male to female ratio was $1.75: 1$. Mean age of the patients was 17.06 years. There were 18 patients $\leq 15$ years of age, out of whom $72.22 \%$ were males, while out of 26 patients $>15$ years of age, male patients were $57.69 \%$.

A total of four symptoms (Itching, Discharge, Photophobia and Watering) and four signs (Conjunctival hyperemia, papillary hypertrophy, Horner Trantas spots and punctate keratitis) were analyzed. Mean values of individual symptoms and signs were compared at baseline and at each follow-up visit (Tables 2, 3). All symptoms like itching, discharge, photophobia and watering showed improvement with respect to baseline (Table 2). Reduction in itching and watering was statistically significant from $4^{\text {th }}$ week onwards, while reduction in discharge and photophobia was observed from $2^{\text {nd }}$ week onwards. Improvement in symptoms was maximum at $12^{\text {th }}$ week with gradual reduction from $2^{\text {nd }}$ week onwards in all symptoms (Fig. 1). Conjunctival hyperemia and papillary hypertrophy showed significant reduction from $4^{\text {th }}$ week onwards and were maximum at $12^{\text {th }}$ week (Table 3). However, the other two signs of Horner Trantas spots and punctate keratitis though showed reduction in their intensity, the improvement was not statistically significant when compared to baseline scores (Fig. 2).

\begin{tabular}{|c|c|c|c|}
\hline Age Group Years) & Male & Female & Total \\
\hline$\leq 10$ & $11(22.00)$ & $5(10.00$ & $16(32.00)$ \\
\hline $11-15$ & $4(8.00)$ & $1(2.00)$ & $5(10.00)$ \\
\hline $16-20$ & $6(12.00)$ & $4(8.00)$ & $10(20.00)$ \\
\hline $21-25$ & $8(16.00)$ & $5(10.00)$ & $13(26.00)$ \\
\hline $26-30$ & $3(6.00)$ & $3(6.00)$ & $6(12.00)$ \\
\hline Total & $\mathbf{3 2}(\mathbf{6 4 . 0 0 )}$ & $\mathbf{1 8 ( 3 6 . 0 0 )}$ & $\mathbf{5 0 ( 1 0 0 . 0 0 )}$ \\
\hline Table 1. Age and Sex Distribution of Patients (n=50) \\
\hline
\end{tabular}

Figures in parenthesis indicate percentage. 


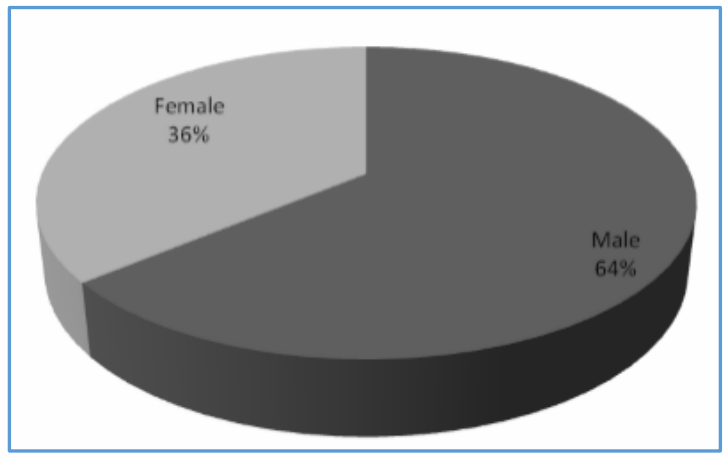

Figure 1. Pie Chart Showing Sex Distribution of Patients

\begin{tabular}{|c|c|c|}
\hline Time Intervals & \begin{tabular}{|c|} 
Mean value \pm \\
SD
\end{tabular} & \begin{tabular}{|c|}
$\begin{array}{c}\text { Statistical Inference } \\
\text { (Unpaired t-Test) }\end{array}$ \\
\end{tabular} \\
\hline \multicolumn{3}{|c|}{ Itching: } \\
\hline Baseline $(\mathrm{n}=50)$ & $1.64 \pm 0.59$ & \\
\hline $2^{\text {nd }}$ week $(n=50)$ & $1.5 \pm 0.70$ & $\mathrm{t}=1.08 ; \mathrm{p}=0.28^{*}$ \\
\hline $4^{\text {th }}$ week $(n=46)$ & $1.10 \pm 0.64$ & $\mathrm{t}=4.30 ; \mathrm{p}<0.0001^{* * *}$ \\
\hline $12^{\text {th }}$ week $(n=44)$ & $0.65 \pm 0.56$ & $\mathrm{t}=8.31 ; \mathrm{p}<0.0001^{* * *}$ \\
\hline \multicolumn{3}{|c|}{ Discharge: } \\
\hline Baseline $(\mathrm{n}=50)$ & $0.76 \pm 0.71$ & \\
\hline $2^{\text {nd }}$ week $(n=50)$ & $0.54 \pm 0.73$ & $\mathrm{t}=1.52 ; \mathrm{p}=0.12^{*}$ \\
\hline $4^{\text {th }}$ week $(n=46)$ & $0.28 \pm 0.50$ & $\mathrm{t}=3.79 ; \mathrm{p}=0.0003^{* * *}$ \\
\hline $12^{\text {th }}$ week $(n=44)$ & $0.15 \pm 0.36$ & $\mathrm{t}=5.14 ; \mathrm{p}<0.0001^{* * *}$ \\
\hline \multicolumn{3}{|c|}{ Photophobia: } \\
\hline Baseline $(\mathrm{n}=50)$ & $0.4 \pm 0.60$ & \\
\hline $2^{\text {nd }}$ week $(n=50)$ & $0.18 \pm 0.48$ & $\mathrm{t}=2.02 ; \mathrm{p}=0.04^{* *}$ \\
\hline $4^{\text {th }}$ week $(n=46)$ & $0.08 \pm 0.28$ & $\mathrm{t}=3.30 ; \mathrm{p}=0.001^{* * *}$ \\
\hline $12^{\text {th }}$ week $(n=44)$ & $0.06 \pm 0.25$ & $\mathrm{t}=3.49 ; \mathrm{p}=0.0007^{* * *}$ \\
\hline \multicolumn{3}{|c|}{ Watering: } \\
\hline Baseline $(\mathrm{n}=50)$ & $1 \pm 0.60$ & \\
\hline $2^{\text {nd }}$ week $(n=50)$ & $0.88 \pm 0.79$ & $\mathrm{t}=0.85 ; \mathrm{p}=0.39^{*}$ \\
\hline $4^{\text {th }}$ week $(n=46)$ & $0.47 \pm 0.69$ & $\mathrm{t}=4.02 ; \mathrm{p}<0.0001^{* * *}$ \\
\hline $12^{\text {th }}$ week $(n=44)$ & $0.25 \pm 0.43$ & $\mathrm{t}=6.87 ; \mathrm{p}<0.0001^{* * *}$ \\
\hline \multicolumn{3}{|c|}{$\begin{array}{l}\text { Table 2. Comparison of Mean Values of Symptoms at } \\
\text { Baseline and at Different Time Intervals }\end{array}$} \\
\hline
\end{tabular}

Not significant; **Significant; ${ }^{* *}$ highly significant.

\begin{tabular}{|c|c|c|}
\hline Time Intervals & $\begin{array}{c}\text { Mean value } \\
\pm \text { SD }\end{array}$ & $\begin{array}{c}\text { Statistical Inference } \\
\text { (Unpaired t-Test) }\end{array}$ \\
\hline \multicolumn{3}{|c|}{ Conjunctival Hyperemia: } \\
\hline Baseline $(n=50)$ & $1.46 \pm 0.61$ & \\
\hline $2^{\text {nd }}$ week $(n=50)$ & $1.32 \pm 0.65$ & $t=1.11 ; p=0.26^{*}$ \\
\hline $4^{\text {th }}$ week $(n=46)$ & $0.89 \pm 0.76$ & $\mathrm{t}=4.06 ; \mathrm{p}<0.0001^{* * *}$ \\
\hline $12^{\text {th }}$ week $(n=44)$ & $0.59 \pm 0.54$ & $\mathrm{t}=7.27 ; \mathrm{p}<0.0001^{* * *}$ \\
\hline \multicolumn{3}{|c|}{ Papillary Hypertrophy: } \\
\hline Baseline $(n=50)$ & $1.04 \pm 0.56$ & \\
\hline $2^{\text {nd }}$ week $(n=50)$ & $1.02 \pm 0.62$ & $t=0.16 ; p=0.86^{*}$ \\
\hline $4^{\text {th }}$ week $(n=46)$ & $0.73 \pm 0.74$ & $\mathrm{t}=2.32 ; \mathrm{p}=0.02^{* *}$ \\
\hline $12^{\text {th }}$ week $(n=44)$ & $0.47 \pm 0.54$ & $\mathrm{t}=5.00 ; \mathrm{p}<0.0001^{* * *}$ \\
\hline \multicolumn{3}{|c|}{ Horner Trantas spots: } \\
\hline Baseline $(n=50)$ & $0.22 \pm 0.54$ & \\
\hline $2^{\text {nd }}$ week $(n=50)$ & $0.26 \pm 0.56$ & $t=0.36 ; p=0.71^{*}$ \\
\hline $4^{\text {th }}$ week $(n=46)$ & $0.17 \pm 0.43$ & $t=0.49 ; p=0.61^{*}$ \\
\hline $12^{\text {th }}$ week $(n=44)$ & $0.11 \pm 0.38$ & $\mathrm{t}=1.12 ; \mathrm{p}=0.26^{*}$ \\
\hline \multicolumn{3}{|c|}{ Punctate Keratitis: } \\
\hline Baseline $(n=50)$ & $0.06 \pm 0.23$ & \\
\hline $2^{\text {nd }}$ week $(n=50)$ & $0.1 \pm 0.36$ & $t=0.66 ; p=0.50^{*}$ \\
\hline $4^{\text {th }}$ week $(n=46)$ & 0 & $t=1.76 ; p=0.08^{*}$ \\
\hline $12^{\text {th }}$ week $(n=44)$ & 0 & $t=1.72 ; p=0.08^{*}$ \\
\hline $\begin{array}{c}\text { Table 3. Compari } \\
\text { Baseline and }\end{array}$ & Mea & $\begin{array}{l}\text { s of Signs at } \\
\text { Intervals }\end{array}$ \\
\hline
\end{tabular}

Not Significant; ${ }^{* *}$ Significant; ${ }^{* * *}$ Highly Significant.

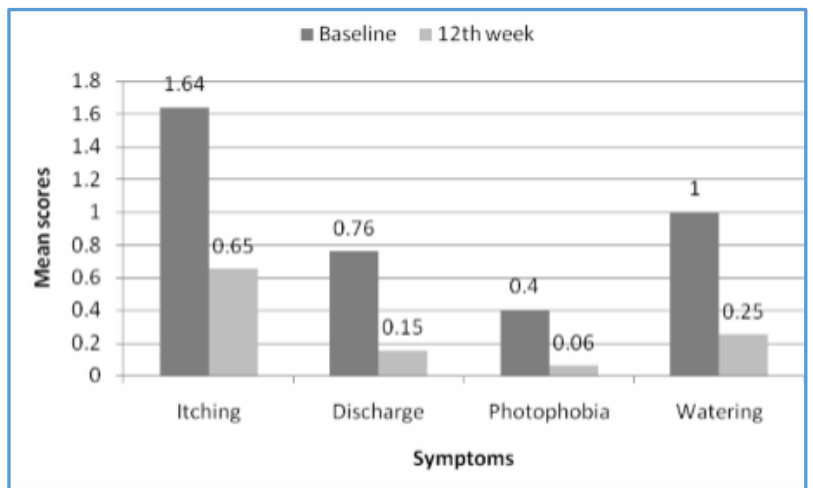

Figure 2. Bar Chart Showing Mean Scores of Symptoms at Baseline and at $12^{\text {th }}$ Week

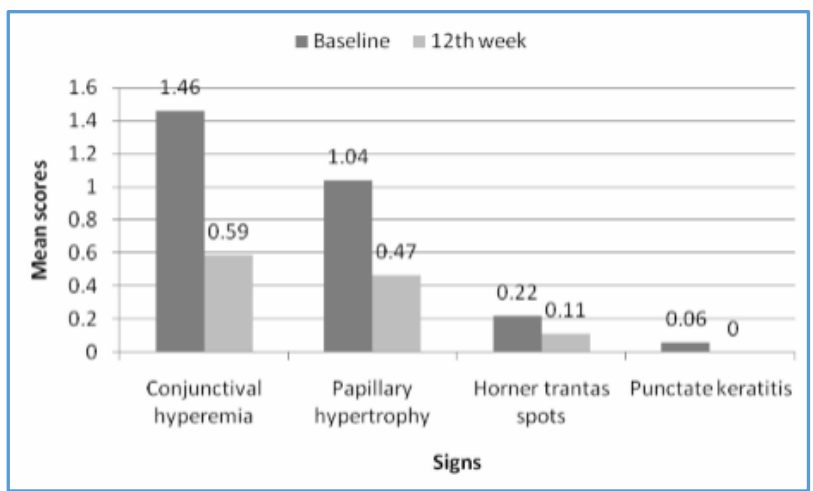

Figure 3. Bar Chart Showing Mean Scores of Signs at Baseline and at $12^{\text {th }}$ Week

\section{DISCUSSION}

Allergic conjunctivitis has a wide geographical distribution and is particularly common in tropics like the Indian subcontinent. ${ }^{6}$ The patient develops disease-related and/or iatrogenic complications with irreparable ocular morbidity. ${ }^{7}$

In our study, it was observed that prevalence of disease was more in males as compared to females, the male-female ratio being $1.75: 1$. The study conducted by Belfort et al. reported a male-female ratio of 5:1 in patients of VKC below the age of 10 years; in patients of AKC male-female ratio was 1:1; in patients of PAC the male- female ratio was 1:4. ${ }^{8}$ Study of Agarwal et al. also showed more prevalence in males $(70.46 \%)$ as compared to females (29.54\%). ${ }^{9}$

The patients showed a gradual but marked improvement in symptoms like itching, discharge, photophobia and watering, especially over 12 weeks. The effect on conjunctival hyperemia and papillary hypertrophy was significant. However, effect on Horner Trantas spots and punctate keratitis was not marked. Study conducted by Agarwal et al. observed that cyclosporine $0.05 \%$ causes a statistically significant reduction of signs and symptoms on $30^{\text {th }}$ day but at $90^{\text {th }}$ day recurrence of signs and symptoms occur but not as severe as baseline. ${ }^{9}$ Ozcan et al. evaluated the efficacy of Cyclosporin in the management of severe allergic conjunctivitis and concluded that it can be used as an effective treatment with a benefit as a steroid sparing agent. 10 Jameel A et al through their study on role of cyclosporine eye drops found that cyclosporine $2 \%$ produced significant improvement in itching, photophobia, discharge, conjunctival hyperemia, punctate keratitis and Horner Trantas spots after 6 weeks treatment period in patients of allergic conjunctivitis. ${ }^{11}$ Arbab TM and Mirza MA in their study 
concluded that cyclosporine $2 \%$ eye drops were safe and effective in the treatment of BKC and a good substitute for

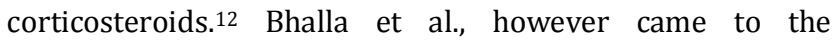
conclusion that topical cyclosporine was ineffective in alleviating signs and symptoms of allergic conjunctivitis. ${ }^{13}$ Their study was conducted on patients with active signs and symptoms of allergic conjunctivitis or those who were not responding to steroids. Our study, on the other hand, evaluated only those patients who had responded to steroids and were not in acute stage.

In our study, cyclosporine was well tolerated by the patients. Apart from mild stinging sensation on instillation no adverse effect was noticed. There was no effect on IOP. In contrast to systemic use, topical application of cyclosporine has few systemic side- effects as only small amount of drug can penetrate into blood stream after topical application. ${ }^{14}$

\section{CONCLUSION}

From our study it can be concluded that topical cyclosporine $0.1 \%$ eye drops can be used to control and improve signs and symptoms of allergic conjunctivitis after the acute phase has been treated with steroids. This will limit the duration of exposure of patients to steroids and reduces the risk of developing steroid-related complications. Also, it was observed that the cyclosporine was safe for topical use.

The present study included only patients of mild and moderate allergic conjunctivitis and was conducted over 12 weeks only. It did not consider those patients who were suffering from severe form of disease or those who did not respond to steroids. We need further studies with more patients and longer follow-up period to support our findings.

\section{REFERENCES}

[1] Wan KH, Chen LJ, Rong SS, et al. Topical cyclosporine in the treatment of allergic conjunctivitis: a metaanalysis. Ophthalmol 2013;120(11):2197-203.

[2] Bleik JH, Tabbara KF. Topical cyclosporine in vernal keratoconjunctivitis. Ophthalmol 1991;98(11):167984.

[3] Whitcup SM, Chan CC, Luyo DA, et al. Topical cyclosporine inhibits mast cell-mediated conjunctivitis. Invest Ophthalmol Vis Sci 1996;37(13):2686-93.
[4] Shoji J, Inada N, Sawa M. Evaluation of novel scoring system named 5-5-5 exacerbation grading scale for allergic conjunctivitis disease. Allergology International 2009;58(4):591-7.

[5] Akpek EK, Dart JK, Watson S, et al. A randomized trial of topical cyclosporine $0.05 \%$ in topical steroidresistant atopic keratoconjunctivitis. Ophthalmol 2004;111(3):476-82.

[6] Howsclaw DS, Whitcher JP, Wong IG, et al. Supratarsal injection of corticosteroid in the treatment of refractory vernal keratoconjunctivitis. Am J Ophthalmol 1996;121(3):243-9.

[7] Anand S, Varma S, Sinha VB. A comparative study on uses of supratarsal triamcinolone injection, topical steroids and cyclosporine in cases of refractory vernal ketatoconjunctivitis. J Evolution Med Dent Sci 2017;6(14):1129-32.

[8] Belfort R, Marbeck P, Hsu CC, et al. Epidemiological study of 134 subjects with allergic conjunctivitis. Acta Ophthalmol Scand Supl 2000;(230):38-40.

[9] Agarwal S, Gupta S, Agarwal B. Role of topical cyclosporine $0.05 \%$ in vernal keratoconjunctivitis. J Indian Med Assoc 2017;115(3):15-8.

[10] Ozcan AA, Ersoz TR, Dulger E. Management of severe allergic conjunctivitis with topical cyclosporine a 0.05\% eyedrops. Cornea 2007;26(9):1035-8.

[11] Jameel A, Moin M, Hussain M. Role of cyclosporine eye drops in allergic conjunctivitis. Pak J Ophthalmol 2009;25(2):104-9.

[12] Arbab TM, Mirza MA. Topical use of cyclosporine in treatment of vernal keratoconjunctivitis. Pak J Ophthalmol 2011;27(3):121-7.

[13] Bhalla S, Sachan SK, Jain AM. Effect of topical cyclosporine $0.05 \%$ in allergic conjunctivitis. Delhi J Ophthalmol 2015;25(3):171-5.

[14] Schultz C. Safety and efficacy of cyclosporine in the treatment of chronic dry eye. Ophthalmol Eye Dis 2014;6:37-42. 